\title{
Hermeneutics, Linguistics of the Text and Extraction of Information, Relevant for the Reader, from the Poetic Text
}

\author{
Manyakhin Alexey Vladimirovich ${ }^{1}$ \\ Assistant Professor of the Tambov State Musical Teacher Training College \\ of S.V. Rachmaninov, \\ Tambov, Russia.
}

(date of receiving: October, 2019; date of acceptance: February, 2020)

\begin{abstract}
The article discusses the correlation of hermeneutics and linguistics of the text. Hermeneutics originated as a doctrine on the interpretation of texts, usually ancient, the meaning of which is difficult to understand because of their remoteness or because the source is not well-preserved. In this case, an understanding of the hidden meaning is achieved by studying the grammatical structure of the text, historical and cultural commentary, psychological research and analysis of the form of the work. Hermeneutics is currently defined as a doctrine of text interpretation.

More recently, a new direction in linguistics has begun to take shape - text linguistics. The linguistics of the text can be characterized as an objective means by which hermeneutics reaches its goal. The author considers the possibility of correlating the hermeneutics and linguistics of the text as a whole and its part.

As a hypothesis, the author proposes a new goal of linguistic analysis of the text to extract information relevant to the reader, to derive information from the text about the environment and the processes taking place in it; comprehension of the state of affairs, of the state of an important, significant issue at the moment.
\end{abstract}

Keywords: Hermeneutics, Interpretation, Text Linguistics, Text, Extraction of Information, Relevant for Reader.

1. E-mail: manyahinav@mail.ru 


\title{
Герменевтика, лингвистика текста и извлечение актуальной для читателя информации из поэтического текста
}

\author{
Маняхин Алексей Владимирович ${ }^{1}$ \\ Старший преподаватель, Тамбовский государственный музыкально- \\ педагогический институт им. С.В. Рахманинова, \\ Тамбов, Россия. \\ (дата получения: октябрь 2019 г.; дата принятия: февраль 2020 г.)
}

\begin{abstract}
Аннотация
В статье рассматривается соотношение герменевтики и лингвистики текста. Герменевтика зародилась как учение об истолковании текстов, как правило древних, смысл которых трудно понять из-за их давности или из-за того, что источник недостаточно хорошо сохранился. При этом понимание скрытого смысла достигается изучением грамматического строя текста, историко-культурным комментированием, психологическими исследованиями и анализом формы произведения. В настоящее время герменевтика определяется как учение об интерпретации текста

Сравнительно недавно начало складываться новое направление в лингвистике - лингвистика текста. Лингвистику текста можно охарактеризовать как объективное средство, с помощью которого герменевтика достигает своей цели. Автор рассматривает возможность соотносить герменевтику и лингвистику текста как целое и его часть.

В качестве гипотезы автор предлагает новую цель лингвистического анализа текста - извлечение актуальной для читателя информации, выведение из текста сведений об окружающем мире и процессах, протекающих в нем; уразумение о положении дел, о состоянии важного, существенного в настоящий момент вопроса.
\end{abstract}

Ключевые слова: Герменевтика, Интерпретация, Лингвистика Текста, Текст, Извлечение Актуальной Для Читателя Информации.

1. E-mail: manyahinav@mail.ru 


\section{Введение}

Существует множество подходов к изучению текста. Текст изучает и литературоведение, и герменевтика, и лингвистика.

Литературоведение давно и пристально изучает художественный текст. Достаточно упомянуть работы Ю.М. Лотмана «Структура художественного текста» и «Анализ поэтического текста».

Современная герменевтика опирается, в первую очередь, на книгу Х.-Г. Гадамера «Истина и метод: основы философской герменевтики». Методы герменевтики используются там, где требуется истолкование языковых явлений, не имеющих однозначной научной интерпретации (см., например, статью Иоанны Ожеховска «Герменевтическое изучение текста Войновского синодика», работы Г.Л. Бузук и Л.Г. Бузук или книгу А.М. Камчатнова «Лингвистическая герменевтика. На материале древнерусских рукописных источников»).

Основу лингвистического анализа художественного текста в России заложил Л.В. Щерба. В своих работах «Опыты лингвистического толкования стихотворений. I. «Воспоминание» Пушкина» и «Опыты лингвистического толкования стихотворений. II. «Сосна» Лермонтова в сравнении с ее немецким прототипом» учёный указал путь, по которому следует идти, исследуя текст художественного произведения - это путь объяснения идеи через семантику и грамматику.

Конечно, цели и задачи изучения текста у каждой науки различны, но объединяет эти науки, на наш взгляд, одно - стремление правильно понять текст. Мы выбрали для анализа два направления в изучении текста: герменевтику и лингвистику текста.

\section{Основная часть}

Большая советская энциклопедия даёт следующее толкование герменевтики: учение об истолковании текстов (здесь и далее выделено мной 
— A.M.), преимущественно древних, первоначальный смысл которых затемнён вследствие их давности или недостаточной сохранности источников. Понимание достигается грамматическим исследованием языка, изучением исторических реалий и вскрытием намёков, смысл которых со временем сделался непонятным; конкретно-психологическими изысканиями и рассмотрением закономерностей формы произведения. (БСЭ 1974. 334)

В Большом энциклопедическом словаре герменевтика определяется как искусство толкования текстов, как учение о принципах их интерпретации. (БЭС 2002. 270)

Толковый словарь иноязычных слов и выражений Л.П. Крысина толкует герменевтику как традицию и способ толкования многозначных или не поддающихся уточнению текстов (большей частью древних). (Крысин 2002. 174)

Развёрнутое определение понятию «герменевтика» даёт Литературный энциклопедический словарь. Герменевтика определяется как толкование текстов, учение о принципах их интерпретации, т.е. о постижении смысла произведения, его идеи и концепции. (ЛЭС 1987. 77)

Задача герменевтики как теории и методологии истолкования текстов состоит, по мнению Е.В. Трубеевой, в прояснении условий, которые делают возможным уразумение смысла текста (Трубеева 2009. 77). Герменевтика изучает слово, фразу и предложение для «вчувствования в субъективность автора и воспроизведения его творческой мысли» (Там же. 78).

Центральной проблемой герменевтики автор называет семантическое содержание текста, соотнесение семантической структуры воспринятого текста (текста в сознании адресата) с семантической структурой задуманного текста (текста в сознании автора) при помощи интерпретации объективного текста (текста как последовательности знаков) (Там же.79).

Итак, герменевтика есть учение об истолковании, интерпретации текста. 
Понятие «герменевтика» неразрывно связано с понятием «интерпретация».

Интерпретация трактуется как перевод на более понятный язык, объяснение, истолкование. В искусстве интерпретация есть избирательное прочтение. В литературоведении интерпретация представляет собой метод истолкования смысла произведения в определённой культурно-исторической ситуации его прочтения. (БЭС 2002. 453)

Интерпретация стремится достигнуть адекватного понимания смысла текста.

Интерпретация художественного текста основывается на рассмотрении формы, которая имеет большой внутренний смысл, значение (ЛЭС 1987. 127 128).

Итак, интерпретация есть истолкование, т.е. разъяснение смысла, изложение точки зрения на что-либо. (Ожегов 2010. 255, 802)

Таким образом, герменевтика объясняет смысл текста, опираясь на анализ лексических и грамматических единиц, на литературный анализ, на синтагматический и прагматический анализ.

Следовательно, герменевтика непосредственно связана с одним из направлений лингвистики - лингвистикой текста.

В Большой российской энциклопедии лингвистика текста определяется как направление лингвистических исследований, предметом которых являются структура, семантика и функционирование текста как языкового произведения. (https://bigenc.ru/linguistics/text/2145176)

В Лингвистическом энциклопедическом словаре лингвистика текста направление лингвистических исследований, объектом которых являются правила построения связного текста и его смысловые категории, выражаемые по этим правилам. (http://tapemark.narod.ru/les/267e.html)

В книге 3.Я. Тураевой лингвистика текста определяется как наука о сущности и организации предпосылок и условий человеческой коммуникации (Тураева 1986. 5). 
Лингвистика текста изучает характер существования текста, характер отражения объективной действительности в тексте или характер отражения реального мира в мире художественного текста, характер языкового оформления текста, личность автора текста (Тураева 1986. 8).

По мнению Трубеевой, лингвистика текста сконцентрировала внимание на формальной синтагматической структуре текста (Трубеева 2009. 79).

Многие исследователи, которые занимаются интерпретацией текстов, вторгаются в область герменевтики (Морозкина 2012. 155). Поэтому предпринимаются попытки создать лингвистическую герменевтику, которая вычленит лингвистическую составляющую из текста и будет её исследовать. Контакт герменевтики и лингвистики текста должен дать в сумме лингвистическую герменевтику, которая станет рассматривать конкретную проблематику взаимодействия мышления, речи, языка в текстовом общении и предлагать конкретные методологические рекомендации. (Г.Л. Бузук, Л.Г. Бузук)

Из всего вышесказанного можно сделать следующий вывод: герменевтика есть учение об интерпретации, истолковании текста, а лингвистика текста есть объективное средство, с помощью которого герменевтика достигает своей цели. Можно даже сказать, что в данном случае герменевтика и лингвистика текста соотносятся как целое и его часть.

Открытым остаются вопросы о том, что такое текст и каковы методы интерпретации текста.

В Большой российской энциклопедии (https://bigenc.ru/linguistics/text/ 4185670) и в Лингвистическом энциклопедическом словаре (http://tapemark. narod.ru/les/507a.html) даётся определение текста как последовательности знаковых единиц, основными свойствами которой являются смысловая связность и цельность.

Лингвистических определений текста существует множество. Общепризнанной является дефиниция, данная И.Р. Гальпериным: текст есть 
«произведение речетворческого процесса, обладающее завершенностью, объективированное в виде письменного документа, литературно обработанное в соответствии с типом этого документа, произведение, состоящее из названия (заголовка) и ряда особых единиц (сверхфразовых единств), объединенных разными типами лексической, грамматической, логической, стилистической связи, имеющее определенную направленность и прагматическую установку» (Гальперин 1981. 18). 3.Я. Тураева понимает текст как «некое упорядоченное множество предложений, объединённых различными типами лексической, логической и грамматической связи, способное передавать определённым образом организованную и направленную информацию. Текст есть сложное целое, функционирующее как структурно-семантическое единство» (Тураева 1986. 11). А художественный текст есть вторичная моделирующая система, в которой сочетаются отражение объективного мира и авторский вымысел. Психолингвистика определяет текст как сложное семантическое образование, обладающее рядом психолингвистических характеристик: цельность, связность, эмотивность, креализованность, прецедентность, скважность, большая степень интерпретативности (реципиенты могут извлечь из него много смыслов) (Белянин 2004. 108).

В качестве рабочего определения мы примем дефиницию 3.Я. Тураевой, потому что в ней выделяется основное свойство текста - информативность. Добавим к этому определению психолингвистическое указание на большую степень интерпретативности текста.

Итак, если герменевтика и лингвистика текста соотносятся как целое и его часть, то лингвистический анализ художественного текста есть метод и лингвистики текста, и герменевтики.

Л.В. Щерба сформулировал цели лингвистического анализа художественного текста - показ лингвистических средств, с помощью которых выражается идейное и связанное с ним эмоциональное содержание 
художественного текста. Он же определил и путь анализа художественного текста - объяснение идеи через семантику лексики и грамматики (Щерба 1957. 97).

Активно развивал теорию и методику анализа поэтического текста Ю.В. Лотман. По его мнению, литературное произведение представляет собой органическое целое, многократно закодированную систему, сложно построенный смысл (Лотман 1972. 38).

Можно сказать, что Ю.В. Лотман в литературоведении движется по тому же пути, что и профессор Щерба в языкознании, - раскрытие идеи через семантику лексики и грамматики, анализируя поэтический текст методом наблюдения над тропами и фигурами речи.

Отдельно следует выделить метод концептуального анализа художественного текста, потому что концептуальное пространство значимо и для национального языка, и для национальной культуры; концепты постоянно присутствуют в культурном сознании, они универсальны и способны к развитию. Концептуальный анализ позволяет выявить и описать культурно значимые концепты и их концептосферу.

Концептуальный анализ художественного текста предполагает выявление набора ключевых слов текста, определение базовых концептов данного концептуального пространства, описание обозначаемого ими концептуального пространства. Трудность здесь представляет выявление ключевых слов текста, т.к. общепринятой методики их определения пока нет.

Наконец мы подошли к главной, на наш взгляд, проблеме - что мы хотим понять в тексте, какую цель мы преследуем, начиная анализировать текст.

Мы считаем, что цель лингвистического анализа текста - извлечение актуальной для читателя информации. Это подразумевает интеграцию традиционных и когнитивных методов. Идея заключается в следующем. Необходимо вывести из текста сведения об окружающем мире и процессах, 
протекающих в нем; осведомиться о положении дел, о состоянии важного, существенного для читателя в настоящий момент вопроса. Рядовому читателю неинтересно рассматривать текст с точки зрения взаимодействия в нём жизненных и литературных планов, в аспекте художественного метода или в историческом контексте. Всё это рядовой читатель оставляет филологам. Читатель обращается к художественному произведению как к «неоценимому источнику познания жизни и законов её борьбы» (Карл Маркс). Изучение художественного произведения как части литературного процесса определённой исторической и культурной эпохи, как выражение творческой индивидуальности писателя должно составлять и составляет содержание обучения в школе. Там же мы должны обучить учеников и самостоятельному чтению, умению извлекать существенную для него в настоящий момент информацию, потому что человек сам отвечает на важнейшие мировоззренческие вопросы: «Кто я? Живу ли я или всего лишь существую? А если живу, то с какой целью?»

Путь анализа текста - объяснение идеи через семантику лексики, включая сюда и грамматическое значение форм употребленных слов, «от семантики слова к содержанию концепта».

Объект исследования - концептуальное (смысловое) пространство текста.

При анализе текста важную роль играют словари, т.к. они раскрывают истинные значения слов.

На наш взгляд, основой для извлечения актуальной для читателя информации может служить алгоритм из учебного пособия Е.В. Скворецкой, представляющий ход анализа стихотворения (Скворецкая 2002):

1. Анализ заглавия: выяснить словарное значение как предположительно раскрывающее важнейшую тему. Указать, используется ли заглавное слово в тексте стихотворения. Сравнить, какова субъективно-оценочная модальность заглавия. 
2. Извлечение содержательно-фактуальной информации (СФИ): факты, события, лица, место действия, время протекания действия.

3. Извлечение содержательно-концептуальной информации (СКИ). Ответить на вопрос: В каком ракурсе автор изображает действительность? Ответ на данный вопрос следует искать в интерпретации пункта 2.

4. На основании пунктов 2 и 3 можно дать интерпретацию текста, т.е. раскрыть содержательно-подтекстовую информацию (СПИ).

Необходимо продолжать поиск универсальных приёмов и методов анализа художественного текста

В качестве примера извлечения из текста актуальной для читателя информации возьмём отрывок из романа Николая Шмелёва «Сильвестр» (Шмелёв 1990. 110):

(1) Послушайте лучше, люди московские, притчу древнюю, многосмысленную, от святых отиов к нам пришедшую. (2) Может, хоть она вас просветит, коли уж своим умом вам до правды не дойти.

(3) Призвал как-то Господь святого Николая и святого Касьяна пред очи Свои светлье, Божественные, и назначил им точный срок. (4) Припозднились святые угодники, торопятся, солнце уже садится, а им ещче идти да идти. (5) И вдруг видят они: валяется у дороги, в грязи, опрокинувшаяся телега с поклажей и волнуется, суетится возле нее какой-то мужичонка самый что ни на есть завалящий. (6) Лошадь-то он выпряг, а телегу обратно на дорогу выпихнуть не может - сил нет.

- (7) Давай, подсобим, - говорит святой Николай святому Касьяну.- (8) Жалко мужика. (9) Одному ему с телегой не совладать.

- (10) Что ты, брат! - отвечает ему святой Касьян. - (11) Tbl забыл, к Кому мы идем? (12) И ты в чистых ризах, $и$ я. (13) Попачкаемся, Господа намего прогневим. 
(14) Да не послушался его святой Николай. (15) Поплевал на руки, влез в самую грязь и вытащил-таки телегу того горемыки обратно на дорогу. (16) Ну, понятно, перемазался весь с головы до ног, да делать нечего, каков есть - таков и есть, надо дальше поспешать.

(17) И вот приходят они к Господу. (18) Видит Господь: стоит перед ним святой Николай грязный, оборванный, прячет от него глаза, стылится себя, а рядом с ним святой Касьян в бельх ризах, и ни пятнышка на них, и лищо его светится светом праздничным, восторженным, и взор его полон любви.

(19) И подивился тогда Господь виду их столь несхожему. (20) И спрашивает Николая: что, дескать, произошло?

- (21) Да так, мол, и так, Господи,- отвечает Ему святой Николай.

- (22) Ну, а ты, Касьян? - спрашивает Господь.

- (23) Да так, мол, и так, Господи,-отвечает и он Ему.

(24) И сказал им тогда Господь: «Что ж, и ты прав, отче Николай, и ты прав, отче Касьян. Но правда ваша разная. И за твою правду, Николай, люди будут праздновать имя твое дважды в год. А твое, Касьян - только в четыре года раз».

(25) Вот так оно и повелось с тех пор: дважды в году, по весне и зимой, чествует народ христианский имя святого угодника Николая, а имя святого Касьяна - только раз в четыре года, 29 февраля. (26) Как говорится, имеющий уши да сльщит! (27) А больще к притче той и добавить нечего: в ней, православнье, вся нама жизнь.

Поскольку мы анализируем отрывок из романа, заглавия у него нет. Вместо анализа заглавия обратим внимание на композицию отрывка. Ведь композиция обладает самостоятельной содержательностью, углубляющей смысл текста. 
Перед нами повествовательный текст, представляющий собой «рассказ в рассказе»: некто хочет поведать слушателям историю, содержащую глубинную «премудрость» моралистического порядка (на это указывает предложение (2)). «Рамка» - предложения первого абзаца и предложения (26)-(27). Данная форма предполагает наличие рассказчика и слушателей, в данном случае - московских жителей.

Есть некто, рассказывающий притчу неопределённому кругу лиц московским жителям. Есть цель - научить людей правде. Есть и мораль.

Притча, рассказанная «людям московским», содержит следующую СФИ.

Господь призвал святых Николая и Касьяна в точно назначенный срок.

\section{Святые припозднились.}

По дороге им попался плохонький мужичонка, с которым случилось несчастие: опрокинулась телега с поклажей.

Святой Николай предлагает помочь мужичонке, а святой Касьян отговаривает, мотивируя тем, что можно попачкаться и этим прогневить Господа.

Святой Николай не послушал и вытащил горемыке телегу, перемазавшись с ног до головы.

Святые явились к Господу. Святой Касьян счастлив видеть Господа, святой Николай стыдится за свой внешний вид.

Господь удивляется их такому разному виду и интересуется причиной. Святые объяснили причину.

Господь признаёт правду каждого и каждого вознаграждает.

Выводом, моралью звучат слова предложения (25): «Вот так оно $и$ повелось с тех пор: дважды в году, по весне и зимой, чествует народ христианский имя святого угодника Николая, а имя святого Касьяна только раз в четыре года, 29 февраля.» 
Какая СКИ содержится в тексте? В каком ракурсе изображается действительность?

Действительность изображается как поиск правды, о чём прямо говорится во вступлении: «притча ... просветит, коли уж своим умом вам до правды не дойти». На то, что речь в притче идёт о поиске правды указывается и в предложении (24), где она упоминается четыре раза: И сказал им тогда Господь: «Что ж, и ты прав, отче Николай, и ты прав, отче Касьян. Но правда ваша разная. И за твою правду, Николай, люди будут праздновать имя твое дважды в год. А твое, Касьян - только в четыре года раз».

В чём же правда? Ответ на этот вопрос заключён в СПИ. Рассказчик в первом же предложении даёт понять, что однозначного ответа нет: и притча многосмысленная, и «имеющий уши да услышит», и в притче «вся наша жизнь».

Конфликт в притче заключается в дилеме - прогневить Господа, помогая людям, или помочь несчастному даже под страхом гнева Божьего. Что важнее: чистым предстать перед Господом или помочь человеку, потеряв при этом чистоту одежды? Важно и то, и другое. Но в приоритете - бескорыстная помощь простым людям. Кто не боится попачкаться, помогая людям, того и чествует народ христианский. Эта позиция рассказчика прямо отражена в предложении (25).

\section{Заключение}

Итак, герменевтика и лингвистика текста могут соотноситься как целое и его часть. Однако каждая из указанных дисциплин имеет свои цели и задачи, поэтому смешивать их представляется нецелесообразным, как и создавать новые дисциплины вроде филологической или лингвистической герменевтики.

В тоже время современный мир требует от человека умения работать с большими объёмами информации, а значит извлечение актуальной для 
читателя информации - это то умение, которое жизненно необходимо и этому умению следует обучать уже в школе.

Извлечение актуальной для читателя информации требует выработки надёжных, универсальных методов и приёмов анализа. Это большая работа, которую нужно вести целенаправленно.

\section{Литература}

1- Белянин В.П. (2004). Психолингвистика: Учебник / В.П. Белянин. - 2-е изд. М.: Изд-во «Флинта»: Московский психолого-социальный институт, -232 с.

2- Большая российская энџиклопедия. [Электронный ресурс]. URL: https://bigenc.ru/linguistics/text/4185670 (дата обращения 05.01.2018)

3- Большая советская эничиклопедия (В 30 томах) (2002). /Гл. ред. А.М. Прохоров. Изд. 3-е. -М.: Изд-во «Советская энциклопедия», 1974. - Т. 18 (Никко - Отолиты). - 644 с.

4- Большой эничиклопедический словарь, (2002). - 2-е изд., перераб. и доп. - М: Изд-во «Большая Российская энциклопедия»; -СПб.: «Норинт».

5- Бузук Г.Л., Бузук Л.Г. Лингвистическая герменевтика: о формировании дисииллинарного статуса. [Электронный ресурс]. URL: https://cyberleninka.ru/article/v/lingvisticheskaya-germenevtika-o-formirovaniidistsiplinarnogo-statusa (дата обращения 05.01.2018)

6- Гальперин, И.Р. (1981). Текст как объект лингвистического исследования / И.Р. Гальперин; АН СССР, Институт языкознания. -М.: Изд-во «Наука», - 156 c.

7- Крысин, Л.П. (2002). Толковый словарь иноязычных слов / Л.П. Крысин 4-е изд., стереотип. -М.: Изд-во «Рус.яз.», 856 с.

8- Лингвистический энцииклопедический словарь. [Электронный ресурс]. URL: http://tapemark.narod.ru/les/507a.html (дата обращения 05.01.2018)

9- Литературный энциклопедический словарь (1987). /Под общ. ред. В. М. Кожевникова, П. А. Николаева. Редкол.: Л. Г. Андреев, Н. И. Балашов, А. Г. Бочаров и др., М.: Изд-во «Сов. Энциклопедия»,-752 с.

10- Лотман, Ю.М. (1972). Анализ поэтического текста. Структура стиха [Пособие для студентов]/ Ю.М. Лотман. -Л.: Изд-во «Просвещение», Ленингр. отделение. - 271 с.

11- Морозкина, Е.А. (2012). Герменевтика в филологии, лингвистике и переводоведении // Вестник Башкирского университета. Т. 17. №1 — c.154-157 
12- Ожегов, С.И. и Шведова, Н.Ю. (2010). Словарь русского языка: 80000 слов и фразеологических выражений / Российская академия наук. Институт русского языка им. В.В. Виноградова. - 4-е изд., дополненное, -М.: ООО «А ТЕМП», $874 \mathrm{c}$.

13- Скворецкая, Е.В. (2002). Языковая организаиия текста (Учебные материалы) / Е.В. Скворецкая. Новосибирск, -268 с.

14- Трубеева, Е.В. Текст и его анализ в риторике, герменевтике и филологии. [Электронный ресурс]. URL: https://cyberleninka.ru/article/v/tekst-i-ego-analiz-vritorike-germenevtike-i-filologii (дата обращения 05.01.2018)

15- Тураева, 3.Я. (1986). Лингвистика текста. Текст: структура и семантика) 3.Я. Тураева. -М.: Просвещение, 126 с.

16- Шмелев Н. (1990). Домострой // Диалог, №13 - с. 110

17- Щерба, Л.В. (1957). Избранные труды по русскому языку/ Л.В. Щерба. -М.: Учпедгиз, $188 \mathrm{c.}$

\section{Bibliography}

1- Beljanin V.P. (2004). Psiholingvistika: Uchebnik / V.P. Beljanin. - 2-e izd. -M.: Izd-vo «Flinta»: Moskovskij psihologo-social'nyj institut, $-232 \mathrm{~s}$.

2- Bol'shaja rossijskaja jenciklopedija. [Jelektronnyj resurs]. URL: https://bigenc.ru/linguistics/text/4185670 (data obrashhenija 05.01.2018)

3- Bol'shaja sovetskaja jenciklopedija (V 30 tomah) (2002). /Gl. red. A.M. Prohorov. Izd. 3-e. -M.: Izd-vo «Sovetskaja jenciklopedija», 1974. - T. 18 (Nikko - Otolity). $-644 \mathrm{~s}$.

4- Bol'shoj jenciklopedicheskij slovar', (2002). - 2-e izd., pererab. i dop. - M: Izdvo «Bol'shaja Rossijskaja jenciklopedija»; -SPb.: «Norint».

5- Buzuk G.L., Buzuk L.G. Lingvisticheskaja germenevtika: o formirovanii disciplinarnogo statusa. [Jelektronnyj resurs]. URL: https://cyberleninka.ru/article/v/lingvisticheskaya-germenevtika-o-formirovaniidistsiplinarnogo-statusa (data obrashhenija 05.01.2018)

6- Gal'perin, I.R. (1981). Tekst kak ob\#ekt lingvisticheskogo issledovanija / I.R. Gal'perin; AN SSSR, Institut jazykoznanija. -M.: Izd-vo «Nauka», - 156 s.

7- Krysin, L.P. (2002). Tolkovyj slovar' inojazychnyh slov / L.P. Krysin 4-e izd., stereotip. -M.: Izd-vo «Rus.jaz.», 856 s.

8- Lingvisticheskij jenciklopedicheskij slovar'. [Jelektronnyj resurs]. URL: http://tapemark.narod.ru/les/507a.html (data obrashhenija 05.01.2018)

9- Literaturnyj jenciklopedicheskij slovar' (1987). /Pod obshh. red. V. M. Kozhevnikova, P. A. Nikolaeva. Redkol.: L. G. Andreev, N. I. Balashov, A. G. Bocharov i dr., -M.: Izd-vo «Sov. Jenciklopedija»,-752 s. 
10- Lotman, Ju.M. (1972). Analiz pojeticheskogo teksta. Struktura stiha [Posobie dlja studentov]/ Ju.M. Lotman. -L.: Izd-vo «Prosveshhenie», Leningr. otdelenie. - $271 \mathrm{~s}$.

11- Morozkina, E.A. (2012). Germenevtika v filologii, lingvistike i perevodovedenii // Vestnik Bashkirskogo universiteta. T. 17. №1 - s.154-157

12- Ozhegov, S.I. i Shvedova, N.Ju. (2010). Slovar' russkogo jazyka: 80000 slov $i$ frazeologicheskih vyrazhenij / Rossijskaja akademija nauk. Institut russkogo jazyka im. V.V. Vinogradova. - 4-e izd., dopolnennoe, -M.: OOO «A TEMP», - 874 s.

13- Skvoreckaja, E.V. (2002). Jazykovaja organizacija teksta (Uchebnye materialy) / E.V. Skvoreckaja. Novosibirsk, -268 s.

14- Trubeeva, E.V. Tekst $i$ ego analiz v ritorike, germenevtike i filologii. [Jelektronnyj resurs]. URL: https://cyberleninka.ru/article/v/tekst-i-ego-analiz-v-ritorikegermenevtike-i-filologii (data obrashhenija 05.01.2018)

15- Turaeva, Z.Ja. (1986). Lingvistika teksta. Tekst: struktura i semantikal Z.Ja. Turaeva. -M.: Prosveshhenie, $126 \mathrm{~s}$.

16- Shmelev N. (1990). Domostroj // Dialog, №13 — s. 110

17- Shherba, L.V. (1957). Izbrannye trudy po russkomu jazyku/ L.V. Shherba. -M.: Uchpedgiz, $188 \mathrm{~s}$.

\section{HOW TO CITE THIS ARTICLE}

Маняхин А. В. (2020). Hermeneutics, Linguistics of the Text and Extraction of Information, Relevant for the Reader, From the Poetic Text. Issledovatel'skiy Zhurnal Russkogo Yazyka $i$ Literatury, 8(2), 203-219.

DOI: 10.29252 /iarll.16.213

URL: http://journaliarll.ir/index.php/iarll/article/view/134

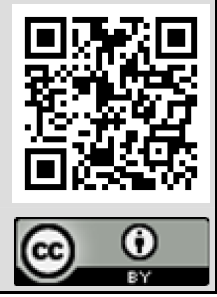




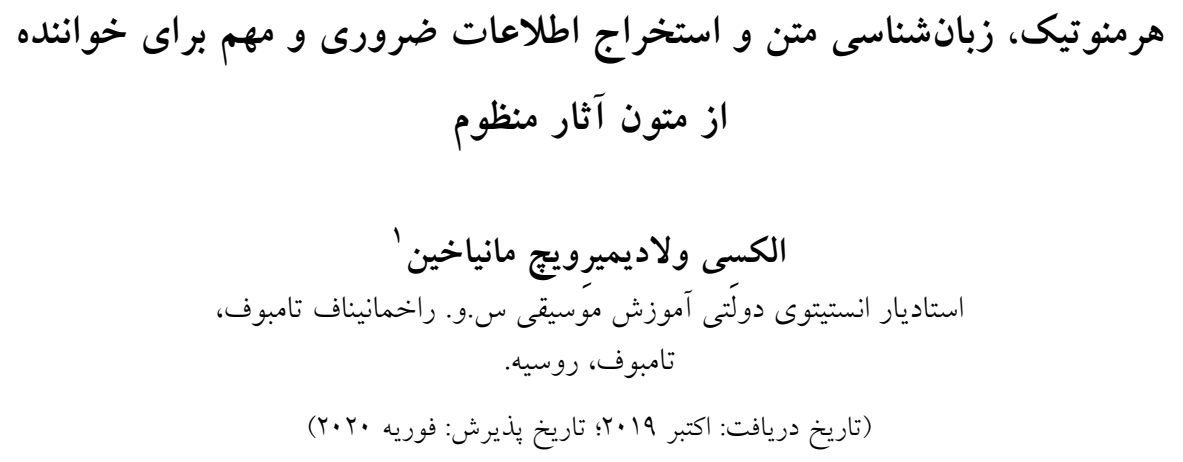

جִكيده

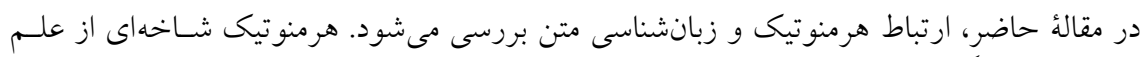

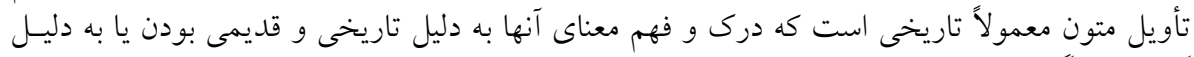

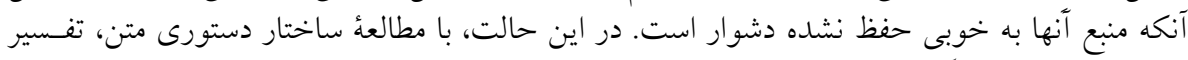

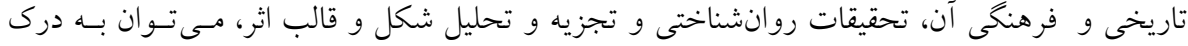

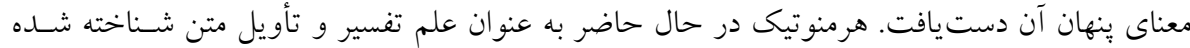

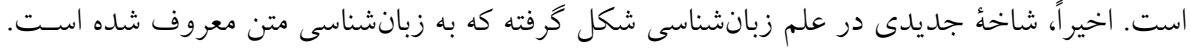

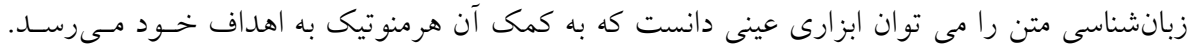

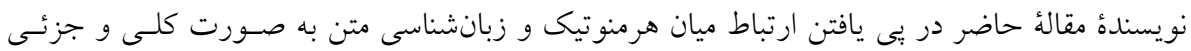

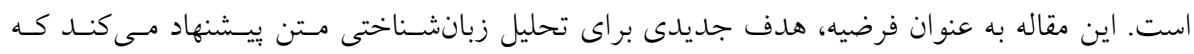

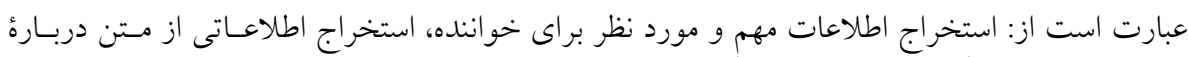

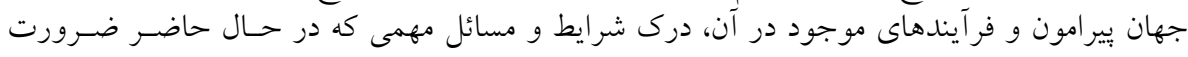

وازگكان كليدى: هرمنوتيك، تفسير و تأويل، زبانشناسى متن، متن، استخراج اطلاعات ضرورى

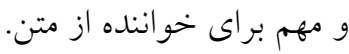

